\title{
Age of Birds at Optimal Production of Eggs: A Polynomial Regression Analysis
}

\author{
Eleazar C. Nwogu \\ Department of Statistics \\ Federal University of Technology \\ Owerri \\ nwoguec@yahoo.com \\ Chigozie K. Acha \\ Department of Mathematics, Statistics \\ and Computer Science \\ Michael Okpara University of Agriculture \\ Umudike \\ specialgozie@yahoo.com
}

\begin{abstract}
This paper discusses the age of birds at optimal production of egg. The objective is to determine the age at which birds are at their best in terms of production of eggs which may be relevant in improving the output of poultry farmers in egg production. To achieve this objective, secondary data on egg production (in grams per day) by age of birds (in weeks, from 18 to 87 weeks) between 2008 and 2010 were collected from poultry farm of the National Root Crop Research Institute (NRCRI), Umudike. This was analysed to determine the appropriate model for age-pattern of egg production among birds aged 18 to 87 weeks. Result of the analysis show that polynomial of order 3 describes the pattern in the egg production data well, but not adequately. The result also shows that the residuals from the fitted polynomial follow the pattern autoregressive process of order 1. Using the fitted model, it was observed that the age of birds at maximum production of eggs is about 44.36 weeks. The egg production corresponding to this age is about 12.14 grams per day. The birds were also found to be at their best, (in terms of egg production ) when they are aged between 34.5 weeks and 54.5 weeks, with egg production of at least 11.07 grams per day Hence, for optimal production of eggs, it is recommended that birds are not kept far beyond 54.5 weeks.
\end{abstract}

Keywords: Egg production, Polynomial Regression, Birds, Cubic model, Poultry product.

\section{Introduction}

In Nigeria, agriculture is the main source of sustenance of a vast majority of the populace. Poultry farming provides food and employment to many people. Poultry products include eggs, fowl and animal droppings. Egg and chicken are the main sources of animal protein for man while animal dropping are used as manure for crop farming. Eggs are of special interest to poultry farmers because eggs can be eaten directly, sold to generate income or hatched into chicken for further breeding. In other words, poultry farmers have a lot to gain from poultry farming in general and egg production in particular. With the ban on imported poultry products, there is need to improve upon the local poultry production to fill this gap. The need for improved egg production, which is the aspect of poultry production examined in this paper, is further heightened by the prevalence of poverty among Nigerians. Poverty breeds malnutrition and low protein intake and since eggs are a cheap source of protein their improved production will help to combat these malaise. 
Acha (2010) had emphasized the need for more efficient production of birds. In the same vein Sacra et al. (2008), Pollock (1997), Molenor et al. (2008) and Schmidt (2008) have stressed on the importance of verifying factors that are relevant to improved poultry production. Egg production, in particular and poultry farming, in general, are affected by many factors which includes feeding, water quality, housing and environmental conditions, temperature, management practices, the body weight of birds, bird strain, age of birds, poultry disease and disturbance [Banerjee (1998); Okereke and Nwogu (2010)]. Any poultry farmer desirous of improving his/her output must, therefore, take these factors into consideration. Many poultry farmers have been able to improve the quality of sanitation and environmental conditions; provide adequate feeding and vaccination for their birds. But bird strain and age of birds remain the factors necessary for improved quantity and quality of egg and poultry products in general that are yet to be controlled. In their study of correlates of eggshell thickness, Okereke and Nwogu (2010) observed that eggshell thickness is significantly associated with age of birds at lay. However, the study did not investigate the nature of this association.

The purpose of this study, therefore, is to determine the nature of the relationship between age of birds and egg production which may be utilized to improve production of egg. The essence is to determine the age range of birds at optimal production of egg that may help farmers to make informed decision on when to cull their birds.

The paper consists of five sections. Section 1 is the introduction, Section 2 presents the methodology of this study and Section 3 examines the need for transformation and choice of appropriate transformation for the study data. The choice of the appropriate regression equation of egg production on age of birds and estimation of the model parameters are discussed in Section 4, while Section 5 contains the summary, recommendation and conclusion.

\section{Methodology}

The data used in this study is a secondary data collected from poultry farm the National Root Crop Research Institute (NRCRI), Umudike. The data is on egg production (in grams per day) by age of birds (in weeks from the age of 18 to 87 weeks) between 2008 and 2010. Since the data is recorded sequentially in time it not likely to be random. The NRCRI farm is selected for this study because it is established with the aim of producing eggs to supplement the feeding of households and provide a steady source of supply to marketers and industries that use eggs as raw material at a reduced price. In other to keep the farm at optimum production level, factors like temperature and humidity are controlled. In fact, during the course of feeding, records are made as to the body weight. This helps the poultry farmers to know how to feed the birds properly. It was recorded that each bird from day old to about 20 weeks consumes cumulatively about $15 \mathrm{~kg}$ of feed. The importance of this record is that it helps in the prediction of the most productive age (in weeks) of these birds in order to have optimum egg production. 
The data was analysed using the method of polynomial regression since age is the only independent variable appearing with various powers. The polynomial regression model is of the form

$$
Y_{i}=f\left(X_{i}\right)+e_{i}
$$

where for the ith week,

$$
f\left(X_{i}\right)=\sum_{k=0}^{p} b_{k} X_{i}^{k}
$$

$\mathrm{Y}_{\mathrm{i}}$ is the egg production (in grams per day), $\mathrm{X}_{\mathrm{i}}$ is the age of birds (in weeks), $b_{k}$ is the $k$ th regression coefficient, $b_{0}$ is intercept, $p$ is the order of the polynomial and $e_{i}$ is the error associated with $\mathrm{Y}_{\mathrm{i}}$ assumed to be uncorrelated and normally distributed with zero mean and constant variance.

In some occasions, the residuals $\left(e_{i}\right)$ may or may not satisfy some or all these conditions. If $\mathrm{e}_{\mathrm{i}}$ is completely random and normally distributed with constant variance, then the fitted model is said to describe the study data adequately. If not, the observed patterns of autocorrelation function (ACF) and partial autocorrelation function (PACF) may be used to identify and fit the appropriate probability model to the residuals in order to achieve adequate fit as recommended by Box et al. (1994). The selected probability model, (i.e. the Autoregressive- Moving average ARMA model) may be fitted using the Box - Jenkins procedure. For details of Box - Jenkins procedure see Box et al. (1994).

In order to evaluate the study data for these assumptions, the normality assumption was investigated by examining the basic statistics of the data (including the mean, median and measures of skewness and kurtosis). Furthermore, the Box - Cox (1964) transformation procedure which jointly investigates the need for and determines the appropriate transformation was also adopted to check the normality assumption and stability of variances. For details of the Box - Cox transformation procedure see Akpanta and Iwueze (2007). However, as noted by Iwu (2009), when data is transformed, the original form of the data, as well as the unit of measure are altered.

The adequacy of the fitted model was also assessed using the JB statistic defined by Jarque and Bera (1980) as

$$
\mathrm{JB}=\frac{\mathrm{n}}{6} \gamma_{1}^{2}+\frac{\mathrm{n}}{24}\left(\gamma_{2}\right)^{2}
$$

where $\gamma_{1}$ and $\alpha=\gamma_{2}-3$ are measures of skewness and kurtosis. The JB statistic is used to test for normality, homoscedasticity and serial independence of regression residuals. When regression residuals are independent and normally distributed with constant mean and variance the JB statistic follows the Chi-square distribution with 2 degrees of freedom. The least squares estimates of the parameters and estimates of the parameters of the probability model were calculated using the MINITAB software. 


\section{Need for and Choice of appropriate Transformation of Egg production Data}

In order to gain more insight into the patterns of variation of trend and variance of the egg production data, the data was partitioned into seven equal parts. The overall and group basic statistics of the egg production data are shown in Table 3.1 while the graphs of the group means $\left(\overline{\mathrm{Y}}_{\mathrm{j}}\right)$ and standard deviations $\left(\mathrm{S}_{\mathrm{j}}\right)$ are shown in Figure 3.1. As Table 3.1 shows, the overall mean (8.4914) is not equal to the median (9.610) as expected in a normal population. The measures of Skewness $\left(\gamma_{1}=-0.700\right)$ and Kurtosis $\left(\gamma_{2}=-0.780\right)$ also do not appear consistent with those of a normal population.

Table 3.1: Basic Statistics of the Egg Production Data

\begin{tabular}{|l|l|r|r|l|r|r|r|r|r|}
\hline $\mathrm{j}$ & Age Group & $\mathrm{n}$ & $\overline{\mathrm{Y}}_{\mathrm{j}}$ & $\mathrm{S}_{\mathrm{j}}$ & $\ln \left(\overline{\mathrm{Y}}_{\mathrm{j}}\right)$ & \multicolumn{1}{l|}{$\ln \left(\mathrm{S}_{\mathrm{j}}\right)$} & $\begin{array}{l}\text { Lag } \\
\mathrm{K}\end{array}$ & $\begin{array}{l}\text { ACF } \\
\mathrm{r}_{\mathrm{k}}\end{array}$ & \multicolumn{1}{l|}{$\begin{array}{l}\text { PACf } \\
\hat{\phi}_{\mathrm{kk}}\end{array}$} \\
\hline 1 & $18.5-26.5$ & 5 & 5.944 & 2.956 & 1.78238 & 1.08384 & 1 & 0.8014 & 0.8014 \\
\hline 2 & $28.5-36.5$ & 5 & 12.042 & 0.171 & 2.48840 & -1.76609 & 2 & 0.6542 & 0.0333 \\
\hline 3 & $38.5-46.5$ & 5 & 11.106 & 0.993 & 2.40749 & -0.00702 & 3 & 0.4646 & -0.1928 \\
\hline 4 & $48.5-56.5$ & 5 & 10.510 & 0.472 & 2.35233 & -0.75078 & 4 & 0.3085 & -0.0566 \\
\hline 5 & $58.5-66.5$ & 5 & 9.488 & 0.333 & 2.25003 & -1.09961 & 5 & 0.1917 & 0.0202 \\
\hline 6 & $68.5-76.5$ & 5 & 7.232 & 0.972 & 1.97852 & -0.02840 & 6 & 0.1262 & 0.0577 \\
\hline 7 & $78.5-86.5$ & 5 & 3.118 & 1.446 & 1.13719 & 0.36880 & 7 & 0.0723 & -0.031 \\
\hline & All & 35 & 8.491 & 3.253 & & & 8 & 0.0261 & -0.0581 \\
\hline & Median & & 9.610 & & & & & & \\
\hline & Skewness & & -0.700 & & & & & & \\
\hline & Kurtosis & & 2.220 & & & & & & \\
\hline
\end{tabular}

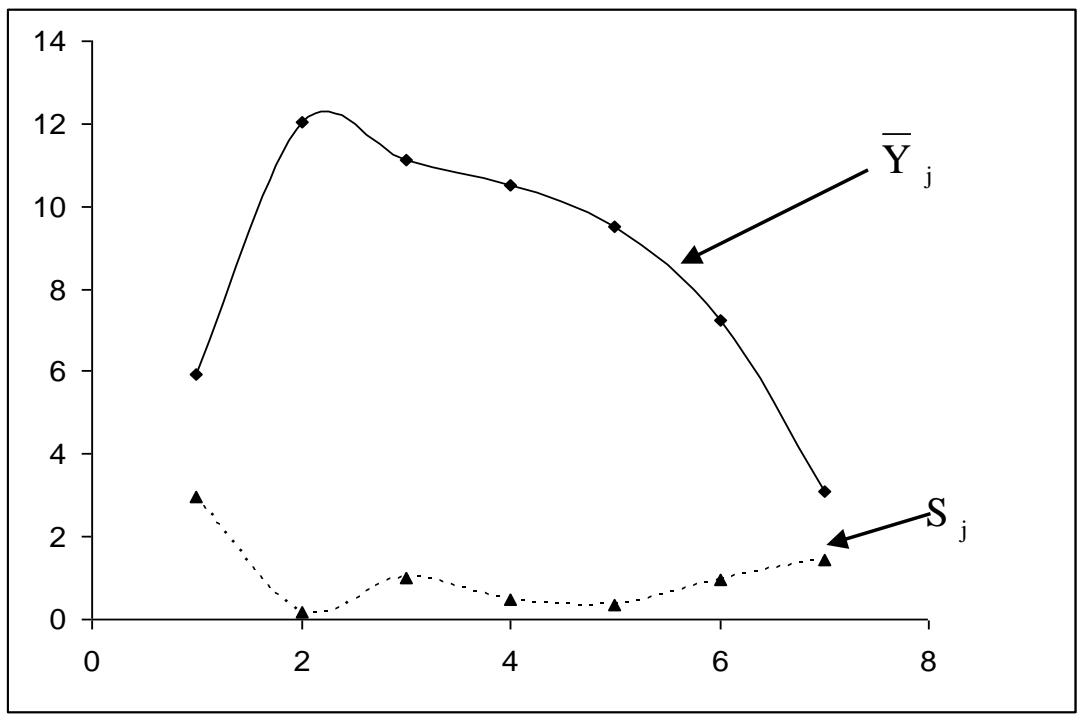

Figure 3.1: Graphs of the group means $\left(\overline{\mathrm{Y}}_{\mathrm{j}}\right)$ and standard deviations $\left(\mathrm{S}_{\mathrm{j}}\right)$ 
The autocorrelation function $\left(\mathrm{r}_{\mathrm{k}}\right)$, shown in Table 3.1, indicates that the data are serially correlated and not independent. Table 3.1 and Figure 3.1 also show that group standard deviations range from about 0.171 to about 2.956 , indicating that the variance may not be constant. Thus, the basic statistics indicate that egg production data may not be independent, normally distributed and may not have constant variance and perhaps, require some transformation.

However, the slope $\left(\beta_{\mathrm{Y}}=-1.35\right)$ of the regression equation of the logarithm of the group standard deviations on the logarithm of the group means (with an associated pvalue of 0.100 ) is not significantly different from zero. This indicates that the data does not need any transformation.

\section{Choice of appropriate model and estimation of model parameters}

The plots of the original data $\left(\mathrm{Y}_{\mathrm{i}}\right)$ and $\mathrm{dth}(\mathrm{d}=1,2$ and 3$)$ order differenced data $\left(\nabla^{\mathrm{d}} \mathrm{Y}_{\mathrm{i}}\right)$ against age of birds $\left(\mathrm{X}_{\mathrm{i}}\right)$ are shown in Figure 4.1 while the plot of the group means $\left(\overline{\mathrm{Y}}_{\mathrm{j}}\right)$ against group number $(\mathrm{j})$ is shown in Figure 3.1. As Figures 4.1(a) and 3.1

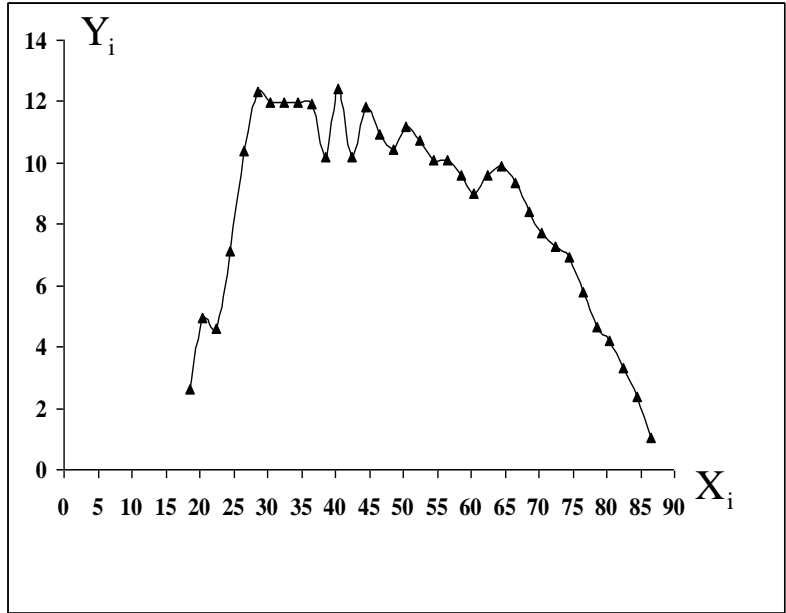

(a) Original Data $\left(\mathrm{Y}_{\mathrm{i}}\right)$

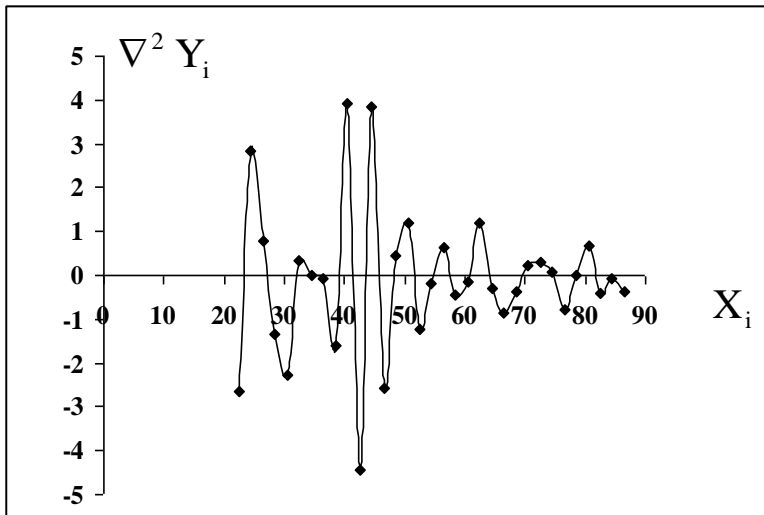

(c) Second order difference $\left(\nabla^{2} Y_{i}\right)$

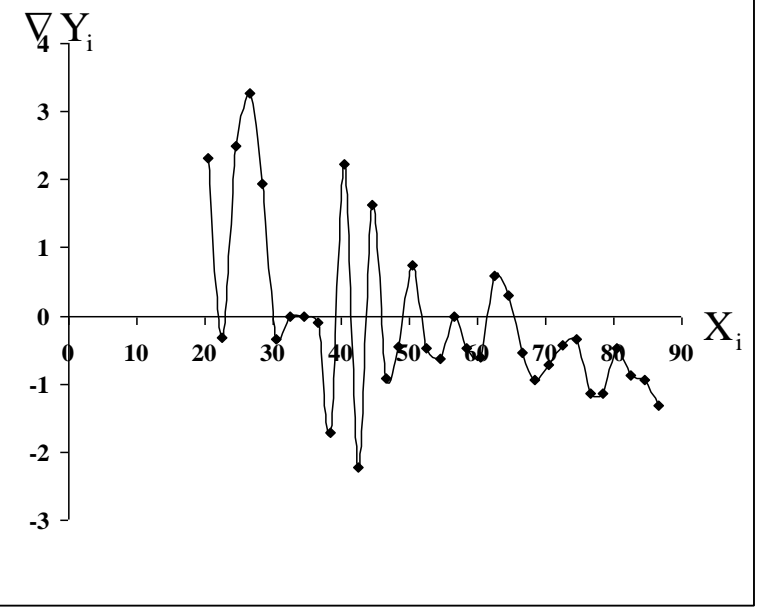

(b) First order difference $\left(\nabla^{1} Y_{i}\right)$

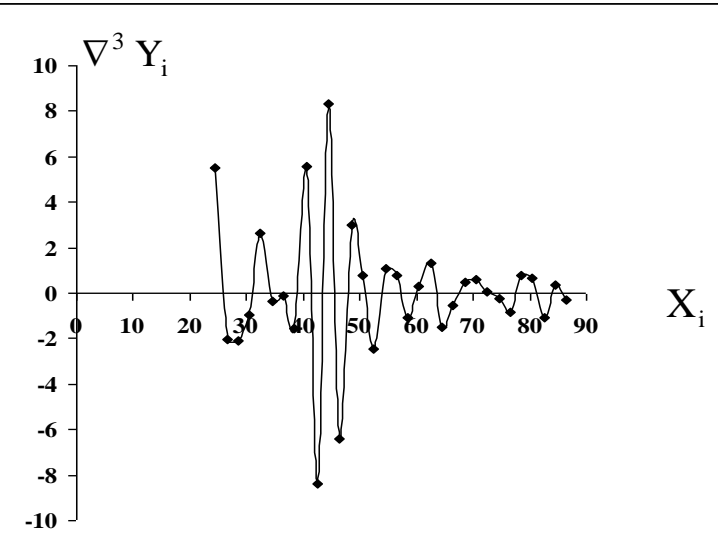

(d) Third order difference $\left(\nabla^{3} Y_{i}\right)$

Figure 4.1: Original data and dth order difference $(\mathrm{d}=1,2$ and 3$)$ of Egg production 
show, the curve which appears to describe the pattern in the study data may be a polynomial of order 2 or 3 . The plots of the second and third order differenced series appear to oscillate about a line through zero, indicating that the differenced series may be stationary in mean. Thus, the choice of polynomials to be entertained lies between the quadratic and cubic curves. Since the quadratic is contained in the cubic equations only the cubic equation was fitted.

The fitted equation is

$$
\hat{f}\left(X_{i}\right)=-15.0711+1.4236 X_{i}-0.0227 X_{i}^{2}+0.0001 X_{i}^{3}
$$

The analysis of variance for the fitted model is shown in Table 4.1. As Table 4.1 shows, the p-values associated with the regression coefficients indicate that the coefficients of all the terms in the model are significantly different from zero. Since the coefficient of the cubic term is significant it means that polynomial of order 3 in Equation (4.1) may be more appropriate to describe the pattern in the study data than the quadratic curve. The value of $\mathrm{R}^{2}$ for the fitted model is 87.5 percent, indicating that about 87.5 percent of the total variation in the egg production data is explained by its dependence on age of birds.

Table 4.1: Analysis of Variance for the fitted curve

\begin{tabular}{|l|r|r|r|r|r|}
\hline SOURCE & DF & SS & MS & F & P \\
\hline Regression & 3 & 314.905 & 104.968 & 72.497 & 0.000 \\
\hline Linear & 1 & 67.728 & - & 7.653 & 0.009 \\
\hline Quadratic & 1 & 232.793 & - & 125.688 & 0.000 \\
\hline Cubic & 1 & 14.384 & - & 9.934 & 0.004 \\
\hline Error & 31 & 44.885 & 1.448 & - & - \\
\hline Total & 34 & 359.790 & - & - & - \\
\hline
\end{tabular}

The actual data $\left(\mathrm{Y}_{\mathrm{i}}\right)$ and the fitted $\left(\hat{\mathrm{Y}}_{\mathrm{i}}\right)$ values of egg production as well as the residuals are shown in Appendix A, while the plots of the actual $\left(\mathrm{Y}_{\mathrm{i}}\right)$ and the fitted $\left(\hat{\mathrm{Y}}_{\mathrm{i}}\right)$ values are shown in Figure 4.2. Appendix A and Figure 4.2 show that the fitted Equation appears to describe the pattern in the egg production data well, especially among birds aged 30.5 weeks and above. 


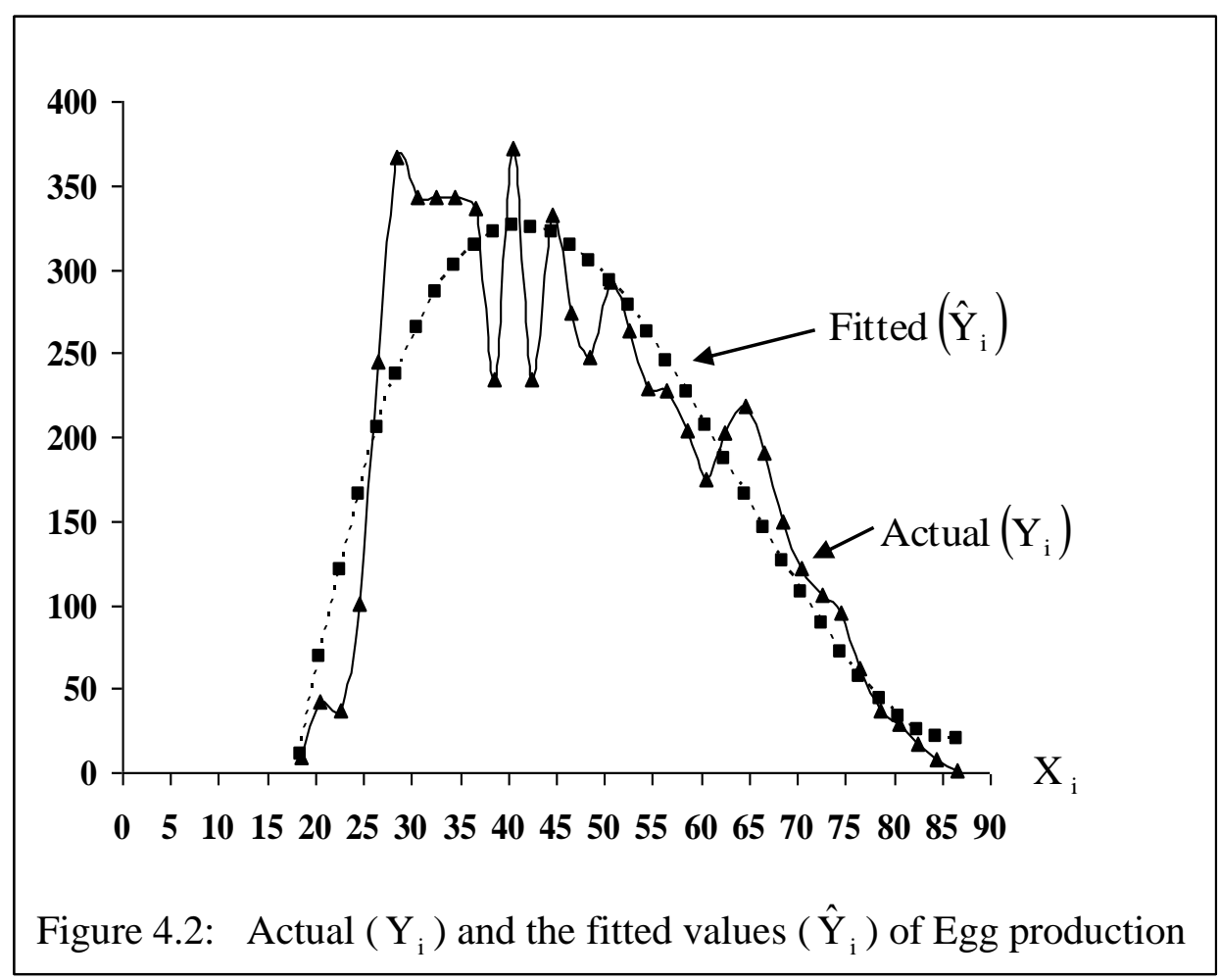

However, to assess the adequacy of the fitted model for the study data, the basic statistics, the autocorrelation function $(\mathrm{ACF})$ and the partial autocorrelation function (PACF) of the residuals

$$
e_{i}=Y_{i}-\hat{Y}_{i}
$$

are calculated and shown in Table 4.2. When compared with the 95\% confidence limits $( \pm 2 / \sqrt{n}= \pm 0.3381)$, the ACF of the residuals $\left(e_{i}\right)$, shown in Table 4.2, appears not to cutoff, while the partial autocorrelation function (PACF) cuts off after lag 1. This implies that the residuals $\left(e_{i}\right)$ are not completely random and that the fitted model, $f\left(X_{i}\right)$ in (4.1) does not describe the pattern in the study data adequately. Since the PACF $\left(\hat{\phi}_{\mathrm{kk}}\right)$ cuts after lag 1, the autoregressive process of order $1, \operatorname{AR}(1)$,

$$
\begin{aligned}
\mathrm{e}_{\mathrm{i}} & =\mathrm{Y}_{\mathrm{i}}-\hat{\mathrm{Y}}_{\mathrm{i}} \\
& =\phi_{0}+\phi_{1} \mathrm{e}_{\mathrm{i}-1}+\mathrm{a}_{\mathrm{i}}
\end{aligned}
$$


Table 4.2: Basic statistics of the residuals from fitted models

\begin{tabular}{|l|r|c|c|c|c|c|c|c|c|}
\hline \multicolumn{5}{|c|}{ Residuals ( } & \multicolumn{4}{c|}{ Residuals $\left(\mathrm{a}_{\mathrm{i}}\right)$ from Eqn (4.3) } \\
\hline \multicolumn{2}{|c|}{ Statistics } & $\begin{array}{c}\text { Lag } \\
\mathrm{K}\end{array}$ & $\begin{array}{l}\text { ACF } \\
\left(\mathrm{r}_{\mathrm{k}}\right)\end{array}$ & $\begin{array}{l}\text { PACF } \\
\left(\hat{\phi}_{\mathrm{kk}}\right)\end{array}$ & \multicolumn{2}{|c|}{ Statistics } & $\begin{array}{l}\text { Lag } \\
\mathrm{K}\end{array}$ & $\begin{array}{l}\text { ACF } \\
\left(\mathrm{r}_{\mathrm{k}}\right)\end{array}$ & $\begin{array}{l}\text { PACF } \\
\left(\hat{\phi}_{\mathrm{kk}}\right)\end{array}$ \\
\hline Mean & 0.0000 & 1 & 0.5612 & 0.5612 & Mean & -0.0056 & 1 & -0.0935 & -0.0935 \\
\hline Median & -0.1306 & 2 & 0.3943 & 0.1158 & Median & 0.0599 & 2 & 0.2117 & 0.2048 \\
\hline Skewness & 0.4062 & 3 & 0.0787 & -0.2692 & Skewness & -0.0100 & 3 & -0.0776 & -0.0449 \\
\hline Kurtosis & 2.6700 & 4 & -0.1147 & -0.1651 & Kurtosis & 3.2400 & 4 & -0.0398 & -0.0968 \\
\hline Std dev & 1.1490 & 5 & -0.2541 & -0.0936 & Std dev & 0.9230 & 5 & -0.1257 & -0.1166 \\
\hline JB & 1.1213 & 6 & -0.2770 & -0.0245 & JB & 0.0846 & 6 & -0.0724 & -0.0698 \\
\hline & & 7 & -0.2862 & -0.0857 & & & 7 & -0.1286 & -0.1060 \\
\hline & & 8 & -0.2423 & -0.0790 & & & 8 & 0.0090 & 0.0016 \\
\hline
\end{tabular}

is fitted tentatively to the residual series $\left(e_{i}\right)$ and estimates of the parameter are shown in Table 4.3. Here, $a_{i}$ is the error associated, assumed uncorrelated and normally distributed with zero mean and constant variance. From Table 4.3 it is clear from the $\mathrm{t}$-value that the

Table 4.3: Final Estimates of Parameters

\begin{tabular}{|l|r|r|r|}
\hline Type & Coef & Std Dev & T \\
\hline AR1 & 0.6142 & 0.1408 & 4.36 \\
\hline Constant & -0.0435 & 0.1593 & -0.27 \\
\hline
\end{tabular}

constant $\left(\phi_{0}\right)$ is not significantly different from zero, while the coefficient of $\operatorname{AR}(1)$ is significant. Therefore, the final estimate of $\phi_{1}$ in the model is 0.6116 and the fitted model is

$$
\mathrm{e}_{\mathrm{i}}=0.6116 \mathrm{e}_{\mathrm{i}-1}+\mathrm{a}_{\mathrm{i}}
$$

The ACF and PACF associated with the residuals $\left(\mathrm{a}_{\mathrm{i}}\right)$ shown in Table 4.2 indicate that the model in (4.4) describes the pattern in $\mathrm{e}_{\mathrm{i}}$ adequately since all of them lie within the $95 \%$ confidence interval $( \pm 2 / \sqrt{\mathrm{n}}= \pm 0.3381)$.

From Equations (4.1) and (4.4), the model which describes the pattern of egg production as a function of age of birds becomes

$$
\hat{f}\left(X_{i}, e_{i}\right)=-15.0711+1.4236 X_{i}-0.0227 X_{i}^{2}+0.0001 X_{i}^{3}+0.6116 e_{i-1}
$$

where $\mathrm{e}_{\mathrm{i}}$ is as defined in (4.3) and $\mathrm{a}_{\mathrm{i}}$ is a completely random and approximately normally distributed process with zero mean, standard deviation $\sigma=0.9223$, skewness $=-0.01$ and Kurtosis $=3.2398$. 
Hence, the age of birds at optimum production of eggs is about 44.36 weeks with $\hat{\mathrm{f}}\left(\mathrm{X}_{\mathrm{i}}\right)=12.14$. In fact grams per day. In fact, the birds appear to be in their best, in terms of egg production, when they are in the age range 34.5 to54.5 weeks. In this age range, their output is at least 11.07 grams per day. Therefore, for optimal production of eggs, it is recommended birds are not kept beyond 54.5 weeks of age.

\section{Summary, Recommendation and Conclusion}

The main objective of this study is to determine the age of birds at optimal production of eggs which may be relevant in improving the output of poultry farmers and poultry products. The relevance of this lies in the fact that it will enable the poultry farmers to know the age of birds that produce the maximum amount of eggs and how long to keep them. To achieve this, the data on egg production (in grams per day) by age of birds collected from the poultry farm of N.R.C.R.I., Umudike was first evaluated for the assumptions of regression analysis. Thereafter, the appropriate model, which adequately describes the observed pattern of egg production by age of birds was identified and fitted.

The result of the analysis shows that, although the assumptions are not completely satisfied, no transformation was suggested. Polynomial of order three was found to describe the pattern in observed data well, though not adequately. Using the pattern of the $\mathrm{ACF}$ and PACF of the residuals from the fitted polynomial, the autoregressive process of order 1 was identified and fitted to the residuals. The fitted model shows that the age of the birds at maximum is about 44.36 weeks. The corresponding egg production at this is about 12.14 grams per day. The birds were also found to be at their best, in terms of production of eggs when they are aged 34.5 weeks to 54.5 weeks, when their output is at least 11.07 grams. per day

Hence, for optimal production of eggs, it is recommended that birds are not kept beyond 54.5 weeks.

\section{References}

1. Acha, C.K. (2010). Impact of Housing and Age of Birds on Egg production. International Journal of Numerical Mathematics, 5(2), 275 - 298.

2. Akpanta A.C and Iwueze, I. S. (2007). On the effect of logarithmic transformation on Multiplicative time series model. Ph.D. thesis Abia State University, Uturu, Nigeria.

3. Banerjee, G.C. (1998). A text Book of Animal Husbandary, Eight Edition, Oxford and IBH Publishing Co. Pvt, New Delhi.

4. Bartlett, M.S (1947). The use of transformation. Biometric Bulletin, 3, 36-52.

5. Bland, J.M. and Attman, J.M. (1996). Statistics Notes, Transforming data. British Medical Journal, London, 312, 770.

6. Box, G. E. P. and D. R. Cox (1964). An analysis of transformations. J. Roy. Statist. Soc., B, 26, 211-243. 
7. Box, G.E.P., Jenkins G.M. and Reinsel, G.C. (1994). Time series Analysis; forecasting and control. Prentice-Hall, New Jersey.

8. Iwu H.C. (2009). Transformation and Decomposition of Multiplicative time Series Model, Ph.D Thesis Abia State University, Uturu Nigeria.

9. Jarque, O.M. and Bera, A.R. (1980). Efficient tests of normality, homoscedasticity and serial independence of regression residuals. Econometrics Letters, 6(3), 255 - 259.

10. Okereke, O. E. and Nwogu, E. C. (2010). Correlates of Eggshell thickness. Global Journal of Pure and Applied Sciences, 16(2), 261 - 268.

11. Molenar, R, Reijrink I.A.M: Merjerhof, R. and Van Den Brand, H. (2008). Relationship between Hatchiling Length and weight on later productive performance of Broilers. World's Poultry Science Journal, 64, 599 - 604.

12. Pollock, D. L. (1997). Maximizing Yield. Poultry Science 76, 1131 - 1133.

13. Sacra, M., Boga, S and Yamak, U. S. (2008). Effects of Space Allowance on Egg Yield, Egg Quality and Plumage Condition of laying Hens in Battery Cage. Czech Journal of Animal Science 8(53), 116 - 121.

14. Schmidt, G. S. (2008). Evaluation of Technical and Economic Impacts of High density Broiler production in an integrated system. Revista Brasitera de Ciencia Avicola, 3(10), 1516 - 1520. 
Appendix A: Actual $\left(Y_{i}\right)$, the fitted values $\left(\hat{Y}_{i}\right)$ of Egg production and Residuals $\left(e_{i}\right)$ from the fitted model (4.1)

\begin{tabular}{|c|c|c|c|c|}
\hline $\mathrm{i}$ & $\mathrm{X}_{\mathrm{i}}$ & $\mathrm{Y}_{\mathrm{i}}$ & $\hat{\mathrm{Y}}_{\mathrm{i}}$ & $e_{i}$ \\
\hline 1 & 18.5 & 2.63 & 4.1117 & -1.4817 \\
\hline 2 & 20.5 & 4.95 & 5.4122 & -0.4622 \\
\hline 3 & 22.5 & 4.62 & 6.5796 & -1.9596 \\
\hline 4 & 24.5 & 7.12 & 7.6189 & -0.4989 \\
\hline 5 & 26.5 & 10.40 & 8.5346 & 1.8654 \\
\hline 6 & 28.5 & 12.34 & 9.3317 & 3.0083 \\
\hline 7 & 30.5 & 11.99 & 10.015 & 1.9750 \\
\hline 8 & 32.5 & 11.99 & 10.589 & 1.4010 \\
\hline 9 & 34.5 & 11.99 & 11.0588 & 0.9312 \\
\hline 10 & 36.5 & 11.90 & 11.4289 & 0.4711 \\
\hline 11 & 38.5 & 10.19 & 11.7043 & -1.5143 \\
\hline 12 & 40.5 & 12.41 & 11.8896 & 0.5204 \\
\hline 13 & 42.5 & 10.19 & 11.9897 & -1.7997 \\
\hline 14 & 44.5 & 11.83 & 12.0093 & -0.1793 \\
\hline 15 & 46.5 & 10.91 & 11.9532 & -1.0432 \\
\hline 16 & 48.5 & 10.45 & 11.8261 & -1.3761 \\
\hline 17 & 50.5 & 11.20 & 11.633 & -0.4330 \\
\hline 18 & 52.5 & 10.73 & 11.3784 & -0.6484 \\
\hline 19 & 54.5 & 10.09 & 11.0672 & -0.9772 \\
\hline 20 & 56.5 & 10.08 & 10.7042 & -0.6242 \\
\hline 21 & 58.5 & 9.61 & 10.2941 & -0.6841 \\
\hline 22 & 60.5 & 9.00 & 9.8418 & -0.8418 \\
\hline 23 & 62.5 & 9.59 & 9.3519 & 0.2381 \\
\hline 24 & 64.5 & 9.89 & 8.8293 & 1.0607 \\
\hline 25 & 66.5 & 9.35 & 8.2787 & 1.0713 \\
\hline 26 & 68.5 & 8.42 & 7.7050 & 0.7150 \\
\hline 27 & 70.5 & 7.71 & 7.1128 & 0.5972 \\
\hline 28 & 72.5 & 7.29 & 6.5070 & 0.7830 \\
\hline 29 & 74.5 & 6.94 & 5.8924 & 1.0476 \\
\hline 30 & 76.5 & 5.80 & 5.2736 & 0.5264 \\
\hline 31 & 78.5 & 4.66 & 4.6556 & 0.0044 \\
\hline 32 & 80.5 & 4.19 & 4.0430 & 0.1470 \\
\hline 33 & 82.5 & 3.31 & 3.4406 & -0.1306 \\
\hline 34 & 84.5 & 2.37 & 2.8532 & -0.4832 \\
\hline 35 & 86.5 & 1.06 & 2.2857 & -1.2257 \\
\hline
\end{tabular}

